\title{
Impact of Ecological Related Innovations Enhancing the Efficiency of Corporate Environmental Responsibility
}

\author{
Yao Sidoine Goli ${ }^{*}$, Jianmu Ye1, Yongling Ye², Bomboma Kalgora ${ }^{3}$ \\ ${ }^{1}$ School of Management, Wuhan University of Technology, Wuhan, China \\ ${ }^{2}$ Business School of Yulin Normal University, Guangxi, China \\ ${ }^{3}$ School of Economics \& Management, Shanghai Maritime University, Shanghai, China \\ Email: ^golikid2@hotmail.com, jianmuye@126.com, 56083231@qq.com, research.kb@outlook.com
}

How to cite this paper: Goli, Y.S., Ye, J.M., Ye, Y.L. and Kalgora, B. (2020) Impact of Ecological Related Innovations Enhancing the Efficiency of Corporate Environmental Responsibility. American Journal of Industrial and Business Management, 10, 191-217. https://doi.org/10.4236/ajibm.2020.101013

Received: December 29, 2019

Accepted: January 18, 2020

Published: January 21, 2020

Copyright $\odot 2020$ by author(s) and Scientific Research Publishing Inc. This work is licensed under the Creative Commons Attribution International License (CC BY 4.0).

http://creativecommons.org/licenses/by/4.0/

\begin{abstract}
The present research paper focused on the phenomenon of innovation as a key solution for business success as it relates to corporate environmental responsibility (CER). The ultimate aim of CER is to prevent and even eliminate, if possible, the harmful impact of business performance on the environment. Every modern company should adhere to the obligations of CER since environmental pollution is a serious hazard that endangers future existence of humankind. For example, it is essential to implement strategies that can contribute to air and water protection. Ecological innovation emerged on the grounds of such urgent needs of environment. Eco-innovation strives to make a transition from business with harmful effects to one of the accountability. Therefore, the present study aimed to review relevant, reliable and up-to-date sources dealing with eco-based innovations in the context of CER. A qualitative research is selected so as to collect sufficient amount of detailed credible data on the issue of concern. The given paper relied on a secondary research encompassing literature review and relevant case studies and a survey as the primary research. Based on the outcomes, several innovations were identified and presented to the target audience.
\end{abstract}

\section{Keywords}

Corporate Environmental Responsibility, Innovations, Environment, Efficiency

\section{Introduction}

Innovation is regarded as a core driver of the development and success of any 
business. The given term derives from the Latin word innovates, which means "to renew, to change, to improve" (Mróz-Gorgoń, 2013, p. 704) [1]. The concept of innovation has different definitions, and some of the most succinct and relevant ones posit it as the implementation of a novice or significantly enhanced product, service, process, or method, whereas others underline that innovation can have continuous connotation, and mean a course of improvement (Reinlie, 2017) [2]. Rexhepi, Kurtishi, and Bexheti (2013) [3] state that "innovation in an implicit way tends to be one of the main drivers of competitiveness" (p. 540). Hence, innovation plays a leading role in business efficiency and predetermines further position of a company within the market.

Innovative technologies must be safe, justified and constructive in order to become a valuable strategic tool for a company. Along with this, the value for society and accountability for the corporate performance has become a topical issue in the modern business world. The standardized kinds of innovation phenomenon include organizational innovation, technological innovation, product innovation, and process innovation. Diverse novice types of innovation have emerged nowadays, reflecting the aforementioned stance of harm to the environment. Eco-innovation and social innovation are among them. According to the report by the Organization for Economic Co-operation and Development (OECD), eco-innovation is defined as "innovation that reflects the concept's explicit emphasis on a reduction of environmental impact, no matter whether or not that effect is intended" (OECD, 2009, p. 13) [4]. Furthermore, it is relevant to highlight that this definition is not limited to innovation in products, methods, and processes, but also encompasses social and institutional structures (OECD, 2009) [4]. Other reports provided by the OECD follow the given definition as well as direction in eco-innovative practical performances. Along with this, it highlights that eco-innovation, or green innovation in other words, is targeted at decrease of resources and energy consumption "while promoting sustainable economic activity" (OECD, 2012, p. 3) [5].

This issue has become urgent today as far as the previous motive behind innovation was almost exclusively for financial gain without taking into account potential or actual harm to the environment or human resources involved in the process. Therefore, while there is nothing objectively wrong about developing innovative technologies as a means of improving the financial standing of a company, another main driver behind innovation should gear towards protecting the environment and indeed humanity. The present research aims to align eco-innovative approaches and efficiency of modern business.

Despite the fact that the phenomenon of eco-innovation is presented and advocated widely in the contemporary business environment, there are still many organizations and particular businesses that focus only on the bottom line even when it causes harm to society and environment. As a direct result of such attitudes, a concept of corporate social responsibility (hereinafter, CSR) and, subsequently, a concept of corporate environmental responsibility (hereinafter, CER) 
were developed and introduced. According to the European Commission, CSR means responsibility each enterprise has for its influence on society and can be achieved by means of "integrating social, environmental, ethical, consumer, and human rights concerns into their business strategy and operations" (European Commission, 2017) [6]. CER implies the accountability of each company for the society concerning its actions (Dummett, 2008) [7]. To be more precise, such organizations recognize that they have a duty to abstain from such types of business activity that can damage natural environment either in direct or indirect way (Lavanya \& Anbalagan, 2012) [8]. Mitigation of the effects is a starting point for currently functioning companies (Salem, Hasnan, \& Osman, 2011) [9]. Gănescu and Dindire (2014) [10] underline that CER is a direct determinant of corporate reputation nowadays.

As a result, the concept of eco-innovation emerges, implying performance aimed at contributing to sustainable development. This, in turn, is designed to create novice products and services for the purposes of both enhancing business value and decreasing of serious environmental damage. The present study aims to review credible, relevant and up-to-date sources dealing with eco-based innovation phenomenon in the context of CER. Both primary and secondary research is employed for the given investigation. A qualitative research is used for the purpose of collecting itemized data sufficient for potentially effective, credible and justified inferences as well as constructive recommendations. The study relies on the literature review, a number of specific case studies, and survey outcomes. The findings based on such a solid background and significant research will provide several ideas on innovative technologies that can be used in practice.

\section{Literature Review}

The present research will require a significant number of sources to be reviewed and analyzed. The core concepts used in the given study include corporate social responsibility, corporate environmental responsibility, and eco-innovation.

\subsection{Eco-Innovation}

The background on innovation and eco-innovation relies on the studies by Kotsemir and Abroskin (2013) [11], Angelo, Jabbour and Galina (2012) [12], Blok and Gremmen (2016) [13], Bocken, Short and Evans (2014) [14], Amit and Zott (2012) [15], Chesbrough (2010) [16], and Rubik et al. (2009) [17]. The notion of innovation is no longer regarded as a creation of something new and better in the contemporary world since such a definition is excessively narrow for the whole range of possibilities that innovative technologies have potential for (Kotsemir \& Abroskin, 2013) [11]. Primarily, innovation constitutes "a panacea for the solution of board range of problems" (Kotsemir \& Abroskin, 2013, p. 3) [11]. The definition of this notion developed by Organization for Economic Cooperation and Development (hereinafter, OECD) is as follows: "the commercial use of new or improved processes or equipment or the introduction of a new approach 
to a Social service. R\&D is only one of these steps" (Kotsemir \& Abroskin, 2013, p. 4) [11]. Hence, innovation is a constructive evolution that contributes to further growth and improvements creating more results in the present and more perspectives for the future.

The issue of natural resources is crucial in the given context. Destructive corporate activities and overall negligence of humankind in terms of use of the natural resources have led to limited availability of these resources, excessive level of environmental pollution and serious transformations in the nature (Schaefer, Goldman, Bartuska, Sutton-Grier, \& Lubchenco, 2015) [18]. Therefore, it is urgent that eco-innovations be implemented on the global scale so as to prevent further damage of natural resources (Sullivan, 2014) [19]. Meena and Singh (2013) [20] underline the ultimate significance of proper management of the remaining natural resources positioning this capacity as a key to a safe and promising future on this planet. Randers (2012) [21] states that it is crucial to start changes immediately if the goal is to reverse course.

The potential of innovation is significant and diverse. Hence, it is employed in different spheres nowadays. Consequently, there are several core kinds of the concept of innovation, as classified by the OECD; namely, product innovation, marketing innovation, process innovation, and organizational innovation (Kotsemir \& Abroskin, 2013) [11]. The type of innovation marked as product innovation entails improvement in technical aspects, adjustments of materials and constituent elements of any final item; in turn, process innovation involves novice accomplishments and improvements in areas of equipment, technology and software; marketing innovation includes contribution to satisfaction of the target audience, customers, as well as expansion to novice markets or acquisition by a company a more perspective position in the given market niche; and the type of organizational innovation implies implementation of newly designed business strategies in the workplace and in cooperation with partners (Kotsemir \& Abroskin, 2013) [11].

Nonetheless, such a classification does not suffice for the needs and priorities of modern society and the business world. Business performance acquires novice implications and values. To be more precise, business activity faces requirements and limitations related to its destructive impact on environment. Business activity often involves depleting important natural resources that are limited and nonrenewable. These resources are referred to as natural capital. Furthermore, nature is impacted by negligent attitude of business sector, and this negative influence results in evident damage, natural catastrophes and hazardous changes in natural processes. Hence, there is a need to adjust all the business processes to an eco-friendly mode and at the same time take responsibility for negative outcomes directly influenced by business activity. Based on such aspects, the notions of ecological innovation have emerged. The phenomenon of ecological innovation (hereinafter, eco-innovation) is a recently developed notion that deals with environmental protection and provision of efficiency of all the introduced 
innovative processes. The definition of this concept by Miedzinski, Doranova, Castel, Roman, and Charter (2013) [22] is as follows: an authentic approach to the issue of modern business activity that is based on "creating business models that are both competitive and respect the environment by reducing resource intensity of products and services" (p. 8).

Angelo, Jabbour, and Galina (2012) [12] underline that ecological innovation entails either incremental enhancements aimed at intensification of the potential of currently existing and applied things, or a radical alteration of the nature of company's performance so as to minimize destructive influence on environment. The alternatives or complete substitutions for the options affecting the nature and its resources are among core concerns the global community faces in the current course of time (Blok \& Gremmen, 2016) [13]. It is hard for the majority of currently functioning companies to transform the course of performance instantaneously as far as it usually affects their revenue and this is not acceptable for the investors that focus only on the profitability of a business venture. In such cases, gradual substitution is the only appropriate recourse. In both cases, innovations are urgently needed. Therefore, eco-based innovative strategies are actively developed, tested and implemented by progressive companies in the current course of time. Nevertheless, a considerable amount of those companies focus only on their bottom line despite the harm they impose on the environment. These companies are major concerns and threats to the global community.

Eco-innovation is a major effort of mankind to implement sustainability as a trade-off between business needs and necessity to save natural capital (Jang, Park, Roh, \& Han, 2015) [23]. Rennings (2011) claims that eco-innovation is not always a win-win situation in terms of achieving sustainability. On the other hand, this is the most optimal tool that can align economic and environmental protection (Rennings, 2011) [24]. Kemp (2010) [25] states that statistical analysis is insufficient for universally acceptable models of implementation and standardized practices. Diaz-Garcia, Saez-Martinez, and Moreno (2015) [26] made a similar observation, claiming that there are still many gaps and poorly systematized areas in the given filed of knowledge. Hence, the given phenomenon is in the process of construction and initial development. Jones, Harrison, and McLaren (n.d.) [27] emphasize the ultimate importance of proper and timely reporting and documented basis for the aforementioned purpose. Nevertheless, there are numerous cases of its successful implementation by different global companies as will be discussed further in this study.

It is also crucial to distinguish between disruptive and incremental types of eco-innovation. According to Miedzinski, Doranova, Castel, Roman, and Charter (2013) [22], "Incremental eco-innovation focuses on improving existing goods and services, whereas disruptive eco-innovation is about thinking outside of the box and bringing completely novel approaches to market" (p. 8). In any case, eco-innovation focuses on the full-cycle perspective rather than on envi- 
ronmentally relevant issues, and such a holistic approach contributes to its overall effectiveness and continuity of positive effects of innovative technologies.

All the facts and challenges of eco-innovation discussed above lead to the conclusion that this process is complex and multi-dimensional. Rizos, Behrens, and Taranic (2015) [28] underline the importance of proper measurement of eco-innovation. Identifying the leaders in eco-innovative practices and those with apparent deficits in it can help in determining the most effective practices, detection of gaps and drawbacks of the applied strategies, and more efficient implementation of eco-innovative tools worldwide. The scholars emphasize the complexity of the phenomenon of eco-innovation caused by its broadness (Rizos, Behrens, \& Taranic, 2015) [28]. Tarnawska (2013) [29] claims that eco-innovation excesses the area of technological progress encompassing alterations in organizational, institutional, cultural and social structures. As a result, indicators of eco-innovation are response indicators, and such indicators tend to evaluate developments eco-innovation incurs at different societal levels. Therefore, expansive research in the scope of evaluation methods should be conducted. OECD (2009) [30] offers an input/output approach that can be applied for effective measurement of eco-innovation. The given approach is based on eco-innovation data. To be more precise, it identifies four categories of eco-innovation data, namely, input measures, intermediate output measures, direct output measures, and indirect impact measures. The examples of these types of data include: R\&D expenditures constitute for the input measures; academic publications and patents in the area of eco-innovation are intermediate output measures; innovations and sales of products from eco-industries that are identified and properly describe form the layer of direct output measures; and alterations or adjustments in absolute environmental influence and resource efficiency are indirect impact measures (OECD, 2009) [30]. Despite such a clearly structured classification of the data, OECD (2009) [30] notes that collection of data is primary challenge for the researchers. The experts in the field of concern posit that it is necessary to collect valid information from surveys and product information databases in order to acquire justified and potentially effective data for subsequent evaluation.

Another approach for measuring eco-innovation efficiency is suggested by the Eco-Innovation Observatory (hereinafter, EIO). EIO (2012) [31] offers an eco-innovation scoreboard that is a constructive tool in the form of composite index indicator aimed to measure effectiveness of eco-innovation activity in different states that are members of the EU. The ultimate purposes of the given scoreboard are to assess the course and effectiveness of eco-innovation's unfolding process in several relevant areas, e.g., environmental scope, R\&D investments, performance of firms and socioeconomic outcomes (EIO, 2012) [31]. The Eco-innovation scoreboard encompasses 16 indicators that address different thematic categories, such as eco-innovation inputs, eco-innovation outputs, eco-innovation activities, socio-economic and environmental outcomes (EIO, 
2012) [31]. Furthermore, the eco-innovation scoreboard proves when properly and regularly used that an indirect connection between some of the aforementioned categories exists (EIO, 2012) [31]. Hence, eco-innovation is a solid asset for the future of sustainable and eco-friendly business.

\subsection{Corporate Social Responsibility}

The basic comprehension and definition of the concept of CSR was formed relying on the studies conducted by Karassin and Bar-Haim (2016) [32], Werther and Chandler (2011) [33], Reinhardt, Stavins, and Vietor (2008) [34], Hawrysz (2013) [35], Grigore (2008) [36], Babiak and Trendafilova (2011) [37], Dahlsrud (2008) [38], Lyon and Maxwell (2008) [39], Delmas and Blass (2010) [40], Hawrysz and Foltys (2016) [41], Minor and Morgan (2011) [42], Basu and Mueller (2012) [43], and Gănescu (2013) [44]. Hence, the concept of CSR is defined as a business approach that encompasses efforts to protect the environment via decreasing harmful practices, philanthropy, contribution to volunteering, and ethical labor practices. The ultimate mission of CSR is to contribute to sustainable development by means of delivering not only economic, but also social and environmental benefits to each stakeholder. Nevertheless, each company decodes the concept of CSR differently, and these differences may depend on economic peculiarities of the country, potential of the company, or development of environmental awareness and eco-friendly practices in the area. Along the same lines, implementation of CSR is a continuous process, which means that each company starts with one or two aspects, growing CSR experiences and contributions with the course of time and development.

\subsection{Corporate Environmental Responsibility}

Definition and study of nature of the term of corporate environmental responsibility (hereinafter, CER) is based on numerous studies, namely, works by Shah (2011) [45], Lavanya and Anbalagan (2012) [8], Holtbrügge and Dögl (2012) [46], Delmas and Blass (2010) [40], Duker and Olugunna (2014) [47], Dummett (2008) [7], Ganescu and Dindire (2014) [10], Karassin and Bar-Haim (2016) [32]. The concept of CER is a comparatively new development in both business and ecological contexts. It appeared at the stage in which business development became a direct hazard to nature and environmental stability (Comanescu, 2010) [48]. Environmental reporting reveals serious damage to the environment caused by performance of huge corporation and public negligence of environmental protection issues (Lodhia, Jacobs, \& Park, 2012) [49]. The following cases that address reporting as a tool of sustainability provision in different areas and via diverse means have been studied and analyzed as a background for the present research: Goswami and Lodhia (2014) [50], Lopatta and Jaeschke (2014) [51], Greiling, Traxler and Stötzer (2015) [52], Hashmi and Al-Habib (2013) [53], Sulaiman and Mokhtar (2012) [54], Sands and Lee (2015) [55], Quental, Lourenço and da Silva (2011) [56], and Herea (2010) [57]. Ingram et al. (2013) 
[58] underline the ultimate role of governmental structures and public contributions to the issue in question. Global significance of corporate accountability in terms of environmental protection is vividly discussed by Pesmatzoglou, Nikolaou, Evangelinos, and Allan (2014) [59].

Environmental consciousness is expected from every person, organization and business unit nowadays in order to prevent serious ramifications imposed by extensive environmental pollution (Duker \& Olugunna, 2014) [47]. Since many corporations ignore the issue of CER based on the financial question, the experts in the field of interest underline that such negligence may result in higher costs for all the stakeholders in the long run (Duker \& Olugunna, 2014) [47]. Along with this, Duker and Olugunna (2014) [47] claim that such negligence can also lead to questionable legitimacy of the company. Moreover, a range of crucial alterations have been detected in the global climate and, subsequently, this has provoked incremental public concern about urgent need of proper environmental protection (Holtbrügge \& Dögl, 2012) [46]. Hence, the awareness of CER and concern about its proper and timely maintenance transformed into an important topic in both academic literature and the modern business world (Holtbrügge \& Dögl 2012) [46].

Karassin and Bar-Haim (2016) [32] posit that the notion of CER is a result of evolution of the concept of corporate social responsibility (hereinafter, CSR), and is positioned as a measure of CSR on diverse levels currently. The evolution of this concept continues nowadays as far as the quantity of environmental problems has increased dramatically, the experts explore and compare the options, develop constructive alternatives, and a significant part of contemporary business world remains reluctant to join the side of business performance that prioritizes CER. Environmental responsibility of business units is curial since its absence endangers the future of the whole global community. If the companies continue their performance without proper accountability for the ramifications of their actions, in the near future humankind will face numerous problems, and some of them will be irreversible in nature, namely, a deficit or complete depletion of crucial natural resources that are currently limited; excessive pollution of environment that will lead to natural disasters and become a hazard for health condition of citizens; and destructive outcomes of irresponsible activity of human beings. There are numerous vivid examples of irrelevant performance of companies, for instance, excessive amount of waste that cannot be utilized properly when consequently returned to the biosphere; notorious carbon emissions affecting the quality of air that provokes negative alterations in atmosphere and is a threat to public health; unjustified extensive use of harmful materials during routine performance. Climate change and hazard of overly pollution are real issues that can put survival of mankind in the nearest future at stake. Hence, the issue of CER has ultimate significance nowadays on the global scale.

\section{Case Studies}

There are several cases that illustrate how ecological innovation can be employed 
as a constructive tool of CER in the current course of time. The cases are selected from those primarily conducted in developing countries, as it is relevant to the ultimate purpose of the given study.

\section{1) Bangladesh}

One of these examples is research on the issue of CER actualization and its potential efficiency in one of the low income countries, Bangladesh, conducted by Belal, Cooper, and Khan (2015) [60]. This country is in the process of transitioning to middle income level, but the significant amount of money required to deal with Bangladesh's urgent environmental issues is a serious obstacle for this process (Belal, Cooper, \& Khan, 2015) [60]. Bangladesh fights numerous challenges of overly competitive globalization trends (Belal, Cooper, \& Khan, 2015) [60]. As Gallhofer, Haslam, and van der Walt (2011) [61] posit, "globalization threatens to silence local voices" (p. 772). Developing countries have serious domestic issues, and this is made more complicated given the pressure to compete in the globalized world and the necessity to adhere to its constantly emerging novice priorities and practices. In such a way, the developing countries find themselves in a challenging and problematic situation.

Brown (2013) [62] states that not only is the environment affected by destructive business activity, but so are the local communities and the public. In such cases, a responsibility of one party affecting the other one should emerge. Hence, the initiative of CER actualization is positioned as a potential solution in the case presented in Bangladesh, as Belal, Cooper, and Khan (2015) [60] examined. The major recommendation in the given case is to involve NGOs in the process of CER actualization. This is regarded as an approach to implementation of "surrogate accountability" conducted via third parties and aimed at contribution to the vulnerable stakeholders. According to the scholars, such an alternative approach to the matter of corporate responsibility is predicted to have more significant and constructive "potential in developing countries where NGOs might act as surrogates for victims of corporate activities and sanction the power wielders on behalf of the vulnerable with a view to redress the balance of power and hold the corporations to account" (Belal, Cooper, \& Khan, 2015, p. 56) [60].

\section{2) Sweden and Denmark}

Another relevant example encompasses process of eco-innovation in contemporary industrial water-service systems (Levidow, Lindgaard-Jorgensen, Nilsson, Skenhall, \& Assimacopoulos, 2016) [63]. The research relies on the cases of two corporations, namely, the Swedish-base automaker Volvo and Danish dairy producer Arla Foods. These companies are well known worldwide and demonstrate how big and successful companies can adjust its processes according to CER. The experts in the field of concern conclude that diverse challenges exist in the process of implementing eco-innovations in the industrial sphere, whereas the general potential of their use is crucial, and further research in this area is recommended (Levidow, Lindgaard-Jorgensen, Nilsson, Skenhall, \& Assimacopoulos, 2016) [63]. To be more precise, Volvo and Arla Foods employ 
environmental policies along with such external drivers as future higher costs and resource scarcity (Levidow, Lindgaard-Jorgensen, Nilsson, Skenhall, \& Assimacopoulos, 2016) [63]. As a result, both companies "represent strong prospects for reducing resource burdens in water-service processes, especially from chemical inputs and wastewater" (Levidow, Lindgaard-Jorgensen, Nilsson, Skenhall, \& Assimacopoulos, 2016, p. 54) [63]. Clearly, these changes require significant effort, finances and proper adjustment of the whole system, and are too complex, challenging, time- and profit-consuming for the cases of developing countries.

3) India

Another case addresses implementation of CER and its efficiency in India. This study was conducted by Chahoud, Emmerling, Kolb, Kubina, Repinski, and Schlager (2007) [64]. The research outcomes reveal that India starts aligning its CSR and CER trends with the practices accepted worldwide (Chahoud et al., 2007) [64]. This study is crucial in demonstrating that implementing CER practices is indeed possible in developing countries nowadays, as India began this process on the global scale ten years ago. There are considerable problematic patterns and drawbacks that endangered overall efficiency of CER processes in the given country. For instance, there was a lack of proper balance between internal and external stakeholders (Chahoud et al., 2007) [64]. Moreover, there was considerable deficit of transparency in community development projects as well as "the involvement of relevant authorities is questionable, and community development may conceal malpractices or violations within a company" (Chahoud et al., 2007, p. 96) [64]. Hence, it is apparent that barriers and difficulties can be experienced by any country, and it is crucial to start now in order to see measurable results.

\section{4) Ethiopia}

Finally, researchers Asfaw, Botes and Mengesha (2017) [65] explore and discuss a case of Ethiopia positioning itself as a relevant example of developing countries actualizing CER. The experts also make an inference that impact of NGOs in the given context is an optimal solution (Asfaw, Botes, \& Mengesha, 2017) [65]. To be more precise, their transparent and constructively designed strategies are expected to make a significant contribution to formation and efficient functioning of green economy in this and similar countries (Asfaw, Botes, \& Mengesha, 2017) [65]. Furthermore, relevant policies should be actualized by means of cooperation with governmental structures, educational institutions, media, and primary stakeholders, as Asfaw, Botes and Mengesha (2017) [65] posit. Diversity of the parties in the given process appears to be challenging at first, but at the same time, it opens access to more opportunities and alternatives in terms of CER implementation.

Based on the present extensive literature review, a model that encompasses the main efficiency criteria was constructed. The framework of this model includes scalability, capacity, security, speed of installation, error handling and validation 
of the data. Each aspect will be addressed in the course of primary study.

\section{Methodology}

The present study relies on both primary and secondary research. Secondary research involves review of credible, reliable and up-to-date sources that feature the core concepts of the research and relevant case studies in the area of interest. Primary research encompasses conducting survey and consequent analysis of the acquired responses. The results lead to the ability to identify several ideas of innovation eligible for further practical use or future, more specific exploration.

\subsection{Research Design}

The given research adheres to the qualitative approach. The reason is that this approach aligns with the major aims of the given research, namely, to provide in-depth insight into the issue in question, to analyze it from different angles and to acquire as much details on the topic as possible. Itemized data and diversity of perspectives contribute to validity and overall potential of the acquired research outcomes (Kumar, 2008) [66]. According to Hancock, Ockleford and Windridge (2009) [67], qualitative research "focuses on reports of experience or on data which cannot be adequately expressed numerically" as well as "focuses on description and interpretation and might lead to development of new concepts or theory, or to an evaluation of an organizational process" (p. 6). Along with this, this type of research uses a flexible, emergent and systematic research process (Hancock, Ockleford, \& Windridge, 2009) [67]. Hence, the given methodology fits the research requirements impeccably since the study seeks to evaluate the prior experience in the area of concern and at the same time to result in novice approach to solution of CER issue under contemporary business terms.

The research question of the present study is as follows: what is the actual impact of eco-based innovation on enhancement of efficiency of CER? The focus of the secondary research will be narrowed down by means of several case studies representing the essential data needed for conclusions and further application of research results. The primary research will employ a survey. According to Fowler (2009) [68], it is crucial to set clear and properly formed questions in order to acquire relevant and reliable data. According to Mathiyazhagan and Nandan (2010) [69], "the instruments have to be carefully developed with regard to the type of questions to be asked, the degree of probing, the sequence of questions" (p. 36). Hence, a survey will be based on the model of criteria of eco-innovation efficiency in terms of CER in order to situate the underlying focus of this study. This framework encompasses criteria of scalability, capacity, security, speed of installation, error handling and validation of the data. Finally, the study will identify directions for further research and potential implications for practice with CER in developing countries.

The given study is regarded as cross-sectional. Such a choice is predetermined 
by the need to observe and collect evidence for subsequent analysis without interventions or modifications of the evidential basis. According to Mann (2003) [70], such a type of research aims at evaluating and identifying the prevalence of an action. All the measurements transpire within one particular point in time, in this particular case, within a week during which the data is collected. The aspect of prevalence is crucial in the given context as far as it challenges relevance and overall effectiveness of novice and essential aspects of modern business world.

\subsection{Research Instrument}

The survey consists of 12 questions. Both open-ended and close-ended questions are included in the survey so as to acquire accurate information on both current tendencies and in-depth insight of the studied phenomenon. The survey will be developed relying on major issues identified during the secondary research and the model of efficiency criteria. To be more precise, the respondents will be asked about dilemmas, challenges and main problematic aspects of eco-innovation in terms of CER. The surveys will be distributed online so as to provide the participants with convenience and a sufficient amount of time to complete it.

\subsection{Study Sample}

The present study involves a comparatively small percentage of the major target audience. To be more precise, the major target audience of the given investigation would be all the entrepreneurs in the world, whereas the given study is conducted in the People's Republic of China and the chosen location is the city of Wuhan, Hubei Province (Central China). The potential audience for this study is invited to partake at three business conferences that are conducted regularly in local business centers. The researchers contacted the organizers of each event and asked for some time after the conferences to present the study mission, aim and offer an invitation to take part in the study. Seven organizers were contacted and three gave consent. The invitation encompassed brief information on the background of the study, identified gaps and highlighted necessity and topicality of the presented study as well as its ultimate purpose, study design and terms of participation. The audience was guaranteed confidentiality of personal data, anonymity of the responses, principle of informed consent, use of the responses in scientific purposes only, and free access to the results of the study. All of those who wanted to participate provided their e-mail addresses.

The overall quantity of the respondents necessary for the study was 100 . A back-up group of 20 more people was formed in case some of the respondents declined to partake, failed to complete the survey or provided incomplete responses. Each individual received a welcome e-mail letter with basic terms, guarantees and form of informed consent. Along with this, each person was assigned to a group. The date the survey was to be distributed and time for its completion ( 1 week) was also mentioned in the letter. As soon as 100 of the respondents 
from the main group provided their consent and confirmed participation, the survey questions were approved, and the surveys were returned by the due date. Only two respondents failed to provide their feedback, so it took 10 additional days to contact the representative of the back-up group and receive their responses.

Once 100 responses were collected, each aspect was analyzed and arranged into a set of inferences. Consequently, the outcomes of the primary and secondary research were compared and aligned or contrasted accordingly. Finally, a concise and comprehensive report was developed, revealing core findings, discrepancies and challenges of the issue in question. The most valuable empirical contribution of the study was a set of innovative ideas designed based on the given research course.

\subsection{Limitations of the Study}

The limitations of the study include a small sample size of participants, biases that might be provoked by the inattentiveness of the respondents or through misunderstanding of the questions, and probability of errors in interpretation of open-ended questions. The small number of participants is validated by intention to acquire itemized data and present an in-depth study of the small-sized sample. The respondents will be asked in the letter attached to the e-mail with the survey to be honest and attentive while completing the survey. Furthermore, in case some biased meanings are detected, clarifications can be made.

\subsection{Ethical Considerations}

The present study will adhere to the following ethical considerations: 1) principle of informed consent. The participants will receive the form of informed consent and will be asked to fill it in as a sign of their willingness to partake in the present study; 2) principle of anonymity. The responses will be anonymous. 3) principle of confidentiality of personal data such as e-mail addresses or first names and surnames; 4) guarantee of the use of responses for scientific purposes of the given study only; 5) and free access to the results of the study once it is finished and presented officially.

\section{Results}

The results acquired via online survey were structured in accordance with the core efficiency criteria presented in the model.

All the participants of the study confirmed that proper implementation of eco-innovative technologies impacted efficiency of CER positively. $78 \%$ of the respondents agreed that eco-innovation always requires making crucial changes, but at the same time leads to better performance outcomes and higher quality of the final product or service level. Some respondents noted in their additional comments to the survey, that CER was impossible without eco-innovation and that awareness of urgent necessity to implement CER in all countries by all 
companies is a key to the future with resources available and natural conditions favorable for all living things on Earth. Seven respondents claimed that CER is being implemented too slowly and such a pace does not suffice for timely changes needed to save the natural capital. One of the participants posited that the course of implementation of eco-innovative technologies endangered the survival of many companies as far as it required much time, efforts, alterations and expenses, and, as a result, the company could face potential bankrupt since revenues could decrease or investors could pull out. This is an important aspect that should be studied further in the future studies.

The results on the criteria of scalability were as follows: $76 \%$ of the respondents stated that eco-innovation contributed to scalability, but only in the long run. Some respondents highlighted that their business needed around two to three years to cross the line of proper scalability after the introduction of eco-innovation technologies (34\%), whereas others stated that qualitative implementation of eco-innovation led to positive results in terms of scalability of the business within a year (28\%). The rest of the respondents stated they had no experience with eco-innovation aligned with scalability issues.

Capacity criterion acquired the following research outcomes: the prevailing majority of respondents (58\%) stated that the primary threat to capacity of the business was eco-innovations; some respondents claimed it was of utmost importance to start eco-innovative practices only when the program aimed at CER provided transparent vision of adjusted performance that did not affect capacity, whereas others claimed it was crucial to start eco-innovative practices as soon as possible since it was hard to construct an impeccable scheme for every type of business without affecting any of the currently studied criteria of efficiency. One of the respondents expressed in the section for additional comments that capacity should be a main concern in the long run, i.e., the capacity decreased in the course of CER actualization is a logical consequence of serious transformations, and should be endured for the sake of the ultimate purpose-better capacity in the future.

Security issue received most of the attention of respondents in the section of additional comments. The following aspects were addressed: according to $98 \%$ of the respondents, security was considered to be the major concern in eco-innovative practices; $44 \%$ of the participants believed that security was a key measure in constructive eco-innovation; $28 \%$ of the respondents claimed they improved security in their businesses via introduction of eco-innovation, and 3\% of them stated innovative technologies were hazardous to their businesses on the initial stage of implementation. $14 \%$ of the participants also highlighted that initial plan of implementation of eco-innovative technologies should include the predictions for potential threats to security and solutions or preventive measures. Furthermore, $7 \%$ of the respondents believed that eco-innovation could become a hazard to overall security measures only in cases in which it was implemented or conducted improperly. Finally, $78 \%$ of the participants also men- 
tioned that security was a consequence of constructive and qualitative eco-innovation and adequately functioning business.

Speed of installation was the next aspect studied in the given research. $77 \%$ of the respondents stated that implementation of eco-innovation was proceeding too slowly. Some respondents commented that they had the following problems because of the low speed of installation: loss of investors because of incremental rates of decreased revenues (11\%); loss of partners because of failed deadlines and terms of their partnership (18\%); reduced sales (12\%); and lower rates in performance in the annual report (6\%). On the other hand, three respondents mentioned that the slow speed of installation could be improved through higher expenses. One of the participants also added that speed of installation in his experience directly depended on the competence of the team. Finally, the need for constructive, maximally detailed plan of installation was mentioned by 28 respondents as a core basis of timely implementation.

Error handling was the most controversially perceived aspect in the context of the given research. To be more precise, $52 \%$ of the respondents believed that it would be impossible to predict and prevent all the crucial errors in the process of implementation of eco-innovative technologies. Furthermore, the main factors contributing to effective error handling were identified as: timely detection of error, highly competent personnel, plan for prompt solution of the errors and their consequent prevention, strong security system, and maximal alignment of business capacity with requirements of eco-innovative technologies. Finally, proper error handling was considered as a significant stage of development of the company in the process of eco-innovation implementation.

Data validation is a final criterion of efficiency used for evaluating positive contribution of eco-innovation to CER in the modern business world. According to the survey completed by those 100 participants, $79 \%$ claimed that data validation was not a problem provided all the previous stages of eco-innovation implementation were conducted properly and timely. Still, the respondents were asked to list the main challenges and drawbacks they faced in the context of data validation, and the most common responses were the following: omission or confusion of data that led to data corruption and security vulnerability; insufficient amount of data necessary for valid outcomes; and improper choice of validation method. A plurality (46\%) highlighted omission or confusion of data as a major reason of unjustified validation results. $23 \%$ of the respondents claimed that such unjustified and corrupted results led to serious problems in overall business performance consequently.

\section{Discussion}

The course of research confirmed some of the inferences and statements acquired in the process of secondary review as well as detected several novice insights in the field of concern. Hence, a list of core findings was formed and will be discussed in this section. 
First, the major concern for all the steps in the course of implementation of eco-innovations should be security. Provided every action is secure, it automatically becomes effective in terms of CER. Security should be ensured by means of prior planning; developing alternatives, preventive measures and solutions; positioning security as an ultimate value in all the actions and decisions; and timely response to errors detected. Security should be preserved beyond just in the initial stage of implementation since each stage of implementation will present novice challenges and risks. Hence, regular evaluation of security level is recommended for consistent course of implementation of eco-innovations.

Second, impact of eco-innovations should contribute to both CER actualization in the company and capacity of the business venture. To be more precise, business owners should position the value of capacity as a long-term target, and understand that any type of adjustment or innovation requires time for the positive effects regarding the whole business process and elimination of destructive influences on environment to take hold. Therefore, eco-innovation should be pre-tested so as the level of capacity remained minimal and acceptable for a particular amount of time needed for the adjustments dedicated to CER actualization. To be more precise, it is recommended that each company construct a plan that outlines the following core elements of eco-innovative technology implementation: estimating the amount of time needed for pausing business activities and for minimal performance determined by adjustments under CER; financial expenses aimed at implementing the adjustments; decrease in standard revenue of the company; changes in human resources and financial obligations related to it; potential changes of cooperation with partners, customers and investors with preliminary evaluated consequences and alternative solutions. Apart from these assessments and predictions, it is important to identify future targets expected from the suggested eco-innovative technologies-financial, environmental and socio-cultural. Due to such a vivid and transparent plan, the company will have a clearer picture of the future, and all the potential drawbacks in performance can be discussed with partners and investors so as to avoid problems and misunderstandings. Clearly, it is a serious challenge for the developing countries where business evolves and functions relying on more short-term and comparatively limited resources.

Third, the speed of implementation will also be featured with several recommendations based on the outcomes of primary research. It is recommended that companies spend more time on proper planning, preliminary research and pre-testing of the selected technologies and methods of implementation than to strive for maximal speed of implementation. Eco-innovation is basically a phenomenon that encompasses crucial changes for almost every type of contemporary business. Therefore, it is better to minimize and prevent risks prior to actual implementation than to deal with errors and problems after hasty implementation. It is especially relevant in the case of developing countries where there is a deficit of finances and such problems can lead even to failure of business units. 
Fourth, it is recommended that companies initiate common changes under CER terms by means of constructive and consistent eco-innovative technologies. "Common changes" refers to combined and properly coordinated efforts of all the local companies targeted at actualization of CER. It is especially relevant when companies with similar destructive effects on environment and society combine their efforts in adjustments to eco-innovative technologies. The logic of the given assumption is as follows: if a particular community has several companies that affect the environment and society in similar ways, eco-innovation in one of them will not suffice for crucial changes needed on the global scale; hence, it is recommended that this issue be discussed with the owners or representatives of all the companies and try to develop a constructive solution. For instance, it can be a process of development of a unified eco-innovative system aimed at actualization of CER priorities and maximal contribution to companies' productivity rate. This is a constructive suggestion as far as the studied cases of implementation of eco-innovative technologies reveal that each implementation requires significant research, planning, and resources, and these processes will be more effective when performed in a systematic and consistent way, especially in the developing countries where all the resources are rather limited.

Fifth, based on the research, it is recommended that companies actualize eco-based innovation in business domain of developing countries with active engagement of NGOs as third parties. Such a practice will provide more support from NGOs as active media partners in this challenging process. Furthermore, NGOs have particular connections and can attract the attention of potential investors and concerned governmental structures on the issue of eco-innovation implementation and transition to CER values and practices in contemporary business world. Finally, cooperation with NGOs will provide the businesses access to a network of companies that have already succeeded in eco-innovation implementation. Such a network will provide the newcomers with valuable recommendations, examples and cases to rely on in practice.

\section{Conclusion and Recommendations}

The present research paper dealt with innovation as a key to efficiency in business based on CER. The given research demonstrated that CER is urgently needed in order to prevent serious natural disasters, preserve natural capital and provide a safe environment for humankind. The ultimate aim of CER phenomenon is to prevent harmful impact of business performance on both the environment and society. CER should become a direct obligation of every company since environmental pollution and deficit of natural resources are serious threats for the future of mankind. As a result, the phenomenon has spurred the ecological innovation that we are witnessing today.

The purpose of the present paper was to provide in-depth insight into potential of eco-innovation on efficiency of CER in the modern business world of developing countries. The aim was actualized via two types of research, namely, 
primary and secondary ones. Secondary research encompassed a review of credible, relevant and up-to-date sources focused on eco-based innovation in the context of CER. Primary research relied on its findings and employed qualitative research in order to collect a sufficient amount of itemized data on the issue in question. The study also relied on four reliable and vivid case studies as a narrowed focus of secondary research. Qualitative research was actualized by means of a survey.

Based on the outcomes, several innovative recommendations were identified and presented to the target audience in the form of a structured list. To be more precise, these recommendations included the following: 1) security is an ultimate measure of efficiency. If every action is secure, it becomes effective in terms of CER automatically. Actualization of security can be achieved via prior planning; development of preventive measures, solutions and alternatives; and timely response to errors detected; 2) the value of capacity should be positioned and treated as a long-term target. It is crucial to develop a comprehension of capacity as a continuous process. Moreover, business owners should understand that all adjustments or innovations require time and effort. Therefore, it is recommended that every business designs a plan that identifies the main elements of eco-innovative technologies implementation; 3) It is recommended that the speed of implementation is improved via better planning, preliminary research and pre-testing of the selected technologies and methods of implementation. Minimization of risks and confidence in the chosen methods are core aspects in the given context; 4) initiative of creation of common changes under CER terms is another constructive recommendation, especially for developing countries. If a local area has several companies that impose destructive influence on environment and society in similar ways, all of them should implement eco-innovation; otherwise, the effect will not suffice for crucial changes needed on the global scale. Therefore, it is recommended that companies implement CER priorities together with other businesses in the area; 5) finally, it is recommended that businesses actualize eco-based innovation in business domain of developing countries with active engagement of NGOs as third parties. The results of the study can be used for further theoretical research as well as for practical implementation in the business sector.

\section{Conflicts of Interest}

The authors declare no conflicts of interest regarding the publication of this paper.

\section{References}

[1] Mróz-Gorgoń, B. (2013) Ecological Innovations in the Concept of Corporate Social Responsibility. http://www.toknowpress.net/ISBN/978-961-6914-02-4/papers/ML13-309.pdf

[2] Reinlie, M.B. (2017) Corporate Social Responsibility (CSR) and Innovation. Master Thesis, University of Oslo, Oslo. 
[3] Rexhepi, G., Kurtishi, S. and Bexheti, G. (2013) Corporate Social Responsibility (CSR) and Innovation. The Drivers of Business Growth? Procedia-Social and Behavioral Sciences, 75, 532-541. https://doi.org/10.1016/j.sbspro.2013.04.058

[4] OECD (2009) Sustainable Manufacturing and Eco-Innovation: Framework, Practice and Measurement-Synthesis Report. OECD, Paris.

[5] OECD (2012) The Future of Eco-Innovation: The Role of Business Models in Green Transformation. https://www.oecd.org/innovation/inno/49537036.pdf

[6] European Commission (2017) Corporate Social Responsibility (CSR). http://ec.europa.eu/growth/industry/corporate-social-responsibility/

[7] Dummett, K. (2008) Corporate Environmental Responsibility (CER). PhD Thesis, RMIT University, Melbourne.

[8] Lavanya, B. and Anbalagan, M. (2012) Corporate Environmental Responsibility with Special Reference to Toyota Motor Corporation. Journal of Business and Management, 4, 8-15. https://doi.org/10.9790/487X-0440815

[9] Salem, M.A., Hasnan, N. and Osman, N. (2011) Can the Eco-Efficiency Represent Corporate Environmental Performance. International Journal of Humanities and Social Science, 1, 183.

[10] Ganescu, C. and Dindire, L. (2014) Corporate Environmental Responsibility-A Key Determinant of Corporate Reputation. CMSS, 2, 48-53.

[11] Kotsemir, M. and Abroskin, A. (2013) Innovation Concepts and Typology-An Evolutionary Discussion.

https://www.hse.ru/pubs/share/direct/document/76780100 https://doi.org/10.2139/ssrn.2221299

[12] Angelo, F.D., Jabbour, C.J.C. and Galina, S.V. (2012) Environmental Innovation: In Search of a Meaning. World Journal of Entrepreneurship, Management and Sustainable Development, 8, 113-121. https://doi.org/10.1108/20425961211247734

[13] Blok, V. and Gremmen, B. (2016) Ecological Innovation: Biomimicry as a New Way of Thinking and Acting Ecologically. Journal of Agricultural Environmental Ethics, 29, 203-217. https://doi.org/10.1007/s10806-015-9596-1

[14] Bocken, N.M.P., Short, S.W., Rana, P. and Evans, S. (2014) A Literature and Practice Review to Develop Sustainable Business Model Archetypes. Journal of Cleaner Production, 65, 42-56. https://doi.org/10.1016/j.jclepro.2013.11.039

[15] Amit, R. and Zott, C. (2012) Creating Value through Business Model Innovation. MIT Sloan Management Review, 53, 41-49.

[16] Chesbrough, H. (2010) Business Model Innovation: Opportunities and Barriers. Long Range Planning, 43, 354-363. https://doi.org/10.1016/j.lrp.2009.07.010

[17] Rubik, F., Scholl, G., Biedenkopf, K., Kalimo, H., Mohaupt, F., Soebech, O., Sto, E., Strandbakken, P. and Turnheim, B. (2009) Innovative Approaches in European Sustainable Consumption Policies. Institut für ökologische Wirtschaftsforschung, Berlin.

[18] Schaefer, M., Goldman, E., Bartuska, A.M., Sutton-Grier, A. and Lubchenco, J. (2015) Nature as Capital: Advancing and Incorporating Ecosystem Services in United States Federal Policies and Programs. Proceedings of the National Academy of Sciences of the United States of America, 112, 7383-7389. https://doi.org/10.1073/pnas.1420500112

[19] Sullivan, S. (2014) The Natural Capital Myth; Or Will Accounting Save the World? Preliminary Thoughts on Nature, Finance and Values. The Leverhulme Centre for the Study of Value School of Environment, Education and Development, The Uni- 
versity of Manchester, Oxford.

[20] Meena, M.S. and Singh, K.M. (2013) Information and Communications Technologies for Natural Resources Management. Journal of Environmental Management Tourism, 2, 77-92. https://doi.org/10.2139/ssrn.2244751

[21] Randers, J. (2012) 2052: A Global Forecast for the Next Forty Years. Chelsea Green Publishing, Vermont.

[22] Miedzinski, M., Doranova, A., Castel, J., Laura, R. and Charter, M. (2013) Eco-Innovate! A Guide to Eco-Innovation for SMEs and Business Coaches. http://cfsd.org.uk/site-pdfs/eco-innovate-sme-guide.pdf

[23] Jang, E.K., Park, M.S., Roh, T.W. and Han, K.J. (2015) Policy Instruments for Eco-Innovation in Asian Countries. Sustainability, 7, 12586-12614. https://doi.org/10.3390/su70912586

[24] Rennings, K. (2011) Eco-Innovation Policies: Concepts, Best Practices and Monitoring. https://www.ecologic.eu/sites/files/presentation/2013/04_rennings_best_practices.pdf

[25] Kemp, R. (2010) Eco-Innovation: Definition, Measurement and Open Research Issues. Economia Politica, 53, 397-420.

[26] Díaz-García, M., Moreno, A. and Saez-Martinez, F. (2015) Eco-Innovation: Insights from a Literature Review. Innovation: Management, Policy and Practice, 17, 6-23. https://doi.org/10.1080/14479338.2015.1011060

[27] Jones, E., Harrison, D. and McLaren, J. (2001) Managing Creative Eco-Innovation: Structuring Outputs from Eco-Innovation Projects. The Journal of Sustainable Product Design, 1.

http://citeseerx.ist.psu.edu/viewdoc/download?doi=10.1.1.427.2330\&rep=rep1\&type $=\mathrm{pdf}$

[28] Rizos, V., Behrens, A. and Taranic, I. (2015) Measuring Progress in Eco-Innovation. CEPS Working Document, No. 409, 1-14.

[29] Tarnawska, K. (2013) Eco-Innovations-Tools for the Transition to Green Economy. Economics and Management, 18, 735-743. https://doi.org/10.5755/j01.em.18.4.4485

[30] OECD (2009) Eco-Innovation in Industry-Enabling Green Growth. OECD, Paris

[31] Eco-Innovation Observatory (2012) Europe in Transition: Paving the Way to a Green Economy through Eco-Innovation. Eco-Innovation Observatory, the European Commission, DG Environment, Brussels.

[32] Karassin, O. and Bar-Haim, A. (2016) Multilevel Corporate Environmental Responsibility. Journal of Environmental Management, 183, 110-120. https://doi.org/10.1016/j.jenvman.2016.08.051

[33] Werther, W.B. and Chandler, D. (2011) Strategic Corporate Social Responsibility: Stakeholders in a Global Environment. 2nd Edition, Sage Publications, Thousand Oaks, CA.

[34] Reinhardt, F.L., Stavins, R.N. and Vietor, R.H.K. (2008) Corporate Social Responsibility through an Economic Lens. Review of Environmental Economics and Policy, 2, 219-239. https://doi.org/10.1093/reep/ren008

[35] Hawrysz, L. (2013) Patronage vs. Implementation of the Corporate Social Responsibility (CSR) Concept in the Public Sector. In: Proceedings of Advanced Research in Scientific Areas, The Slovak Republic, EDIS, Publishing Institution of the University of Zilina, Zilina, 184-187.

[36] Grigore, G. (2008) Corporate Social Responsibility-Strategies in European Style. 
Economics Science Series, 17, 662-665.

[37] Babiak, K. and Trendafilova, S. (2011) CSR and Environmental Responsibility: Motives and Pressures to Adopt Green Management Practices. Corporate Social Responsibility and Environmental Management, 18, 11-24. https://doi.org/10.1002/csr.229

[38] Dahlsrud, A. (2008) How Corporate Social Responsibility Is Defined: An Analysis of 37 Definitions. Corporate Social Responsibility and Environmental Management, 15, 1-13. https://doi.org/10.1002/csr.132

[39] Lyon, T.P. and Maxwell, J.W. (2008) Corporate Social Responsibility and the Environment: A Theoretical Perspective. Review of Environmental Economics and Policy, 1, 1-22.

[40] Delmas, M. and Blass, V.D. (2010) Measuring Corporate Environmental Performance: The Trade-Offs of Sustainability Ratings. Business Strategy and the Environment, 19, 245-260. https://doi.org/10.1002/bse.676

[41] Hawrysz, L. and Foltys, J. (2016) Environmental Aspects of Social Responsibility of Public Sector Organizations. Sustainability, 8, 1-10. https://doi.org/10.3390/su8010019

[42] Minor, D. and Morgan, J. (2011) CSR as reputation insurance: Primum non nocere. California Management Review, 53, 40-59. https://doi.org/10.1525/cmr.2011.53.3.40

[43] Basu, K. and Mueller, M. (2012) CSR Innovation and Corporate Reputation: A Cross-Cultural Perspective Summary. Centre for Corporate Reputation, Oxford University, Oxford, UK.

[44] Gănescu, C. (2013) A Methodology to Assess the Performance of Corporate Social Responsibility. A Study of the European Automotive Sector. Management Strategies Journal, 22, 312-320.

[45] Shah, K.U. (2011) Strategic Organizational Drivers of Corporate Environmental Responsibility in the Caribbean Hotel Industry. Political Sciences, 44, 321-344. https://doi.org/10.1007/s11077-011-9130-x

[46] Holtbrügge, D. and Dögl, C. (2012) How International Is Corporate Environmental Responsibility? A Literature Review. Journal of International Management, 18, 180-195. https://doi.org/10.1016/j.intman.2012.02.001

[47] Duker, J. and Olugunna, M. (2014) Corporate Environmental Responsibilities (CER). A Case of Logistic Companies in Sweden. http://www.diva-portal.org/smash/get/diva2:727457/FULLTEXT01.pdf

[48] Comanescu, M. (2010) Increasing Responsibility towards Environment. Theoretical and Applied Economics, 17, 59-72.

[49] Lodhia, S., Jacobs, K. and Park, Y.J. (2012) Driving Public Sector Environmental Reporting. The Disclosure Practices of Australian Commonwealth Departments. Public Administration and Management, 14, 631-647. https://doi.org/10.1080/14719037.2011.642565

[50] Goswami, K. and Lodhia, S. (2014) Sustainability Disclosure Patterns of South Australian Local Councils: A Case Study. Public Money Management, 34, 273-280. https://doi.org/10.1080/09540962.2014.920200

[51] Lopatta, K. and Jaeschke, R. (2014) Sustainability Reporting at German and Austrian Universities. International Journal of Education Economics and Development, 5, 66-90. https://doi.org/10.1504/IJEED.2014.059868

[52] Greiling, D., Traxler, A.A. and Stötzer, S. (2015) Sustainability Reporting in the Austrian, German and Swiss Public Sector. International Journal of Public Sector 
Management, 28, 404-428. https://doi.org/10.1108/IJPSM-04-2015-0064

[53] Hashmi, M.A. and Al-Habib, M. (2013) Sustainability and Carbon Management Practices in the Kingdom of Saudi Arabia. Journal of Environmental Planning and Management, 56, 140-157. https://doi.org/10.1080/09640568.2012.654849

[54] Sulaiman, M. and Mokhtar, N. (2012) Ensuring Sustainability: A Preliminary Study of Environmental Management Accounting in Malaysia. International Journal of Business Management Science, 5, 85-102.

[55] Sands, J. and Lee, K.H. (2015) Environmental and Sustainability Management Accounting (EMA) for the Development of Sustainability Management and Accountability. Issues of Social Environmental Accountability, 9, 1-4.

[56] Quental, N., Lourenço, J.M. and da Silva, F.N. (2011) Sustainable Development Policy: Goals, Targets and Political Cycles. Sustainable Development, 19, 15-29. https://doi.org/10.1002/sd.416

[57] Herea, W. (2010) Policy and Strategy for Improving Sustainable Social Development Programmes. Environmental Engineering Management Journal, 9, 861-868. https://doi.org/10.30638/eemj.2010.115

[58] Ingram, V., de Grip, K., de Wildt, M.R., Ton, G., Douma, M., Boone, K. and van Hoeven, H. (2013) Corporate Social Responsibility: The Role of Public Policy: A Systematic Literature Review of the Effects of Government Supported Interventions on the Corporate Social Responsibility (CSR) Behaviour of Enterprises in Developing Countries. Policy and Operations Evaluation Department (IOB), Ministry of Foreign Affairs of the Netherlands, The Hague, Amsterdam.

[59] Pesmatzoglou, D., Nikolaou, I.E., Evangelinos, K.I. and llan, S. (2014) Extractive Multinationals and Corporate Social Responsibility: A Commitment towards Achieving the Goals of Sustainable Development or Only a Management Strategy? Journal of International Development, 26, 187-206. https://doi.org/10.1002/jid.2871

[60] Belal, A.R., Cooper, S.M. and Khan, N.A. (2015) Corporate Environmental Responsibility and Accountability: What Chance in Vulnerable Bangladesh? Critical Perspectives on Accounting, 33, 44-58. https://doi.org/10.1016/j.cpa.2015.01.005

[61] Gallhofer, S., Haslam, J. and van der Walt, S. (2011) Accountability and Transparency in Relation to Human Rights: A Critical Perspective Reflecting upon Accounting, Corporate Responsibility and Ways forward in the Context of Globalisation. Critical Perspectives on Accounting, 22, 765-780.

https://doi.org/10.1016/j.cpa.2011.07.002

[62] Brown, E. (2013) Vulnerability and the Basis of Business Ethics: From Fiduciary Duties to Professionalism. Journal of Business Ethics, 113, 489-504. https://doi.org/10.1007/s10551-012-1318-2

[63] Levidow, L., Lindgaard-Jorgensen, P., Nilsson, A., Skenhall, S.A. and Assimacopoulos, D. (2016) Process Eco-Innovation: Assessing Meso-Level Eco-Efficiency in Industrial Water-Service Systems. Journal of Cleaner Production, 110, 54-65. https://doi.org/10.1016/j.jclepro.2014.12.086

[64] Chahoud, T., Emmerling, J., Kolb, D., Kubina, I., Repinski, G. and Schlager, C. (2007) Corporate Social and Environmental Responsibility in India-Assessing the UN Global Compac's Role, The German Development Institute, Bonn.

[65] Asfaw, T.S., Botes, V. and Mengesha, L.G. (2017) The Role of NGOs in Corporate Environmental Responsibility Practice: Evidence from Ethiopia. International Journal of Corporate Social Responsibility, 2, 1-9. https://doi.org/10.1186/s40991-017-0013-0

[66] Kumar, R. (2008) Research Methodology: A Step-by-Step Guide for Beginners.

[67] Hancock, B., Ockleford, E. and Windridge, K. (2009) An Introduction to Qualita- 
tive Research.

https://www.rds-yh.nihr.ac.uk/wp-content/uploads/2013/05/5_Introduction-to-qual itative-research-2009.pdf

[68] Fowler, F.J. (2009) Survey Research Methods. 4th Edition, SAGE, New York. https://doi.org/10.4135/9781452230184

[69] Mathiyazhagan, T. and Nandan, D. (2010) Survey Research Method. Media Mimansa, 34-82.

[70] Mann, C.J. (2003) Observational Research Methods. Research Design II: Cohort, Cross Sectional, and Case-Control Studies. Emergency Medicine Journal, 20, 54-60. https://doi.org/10.1136/emj.20.1.54 


\section{Appendixes}

\section{Appendix 1. Framework}

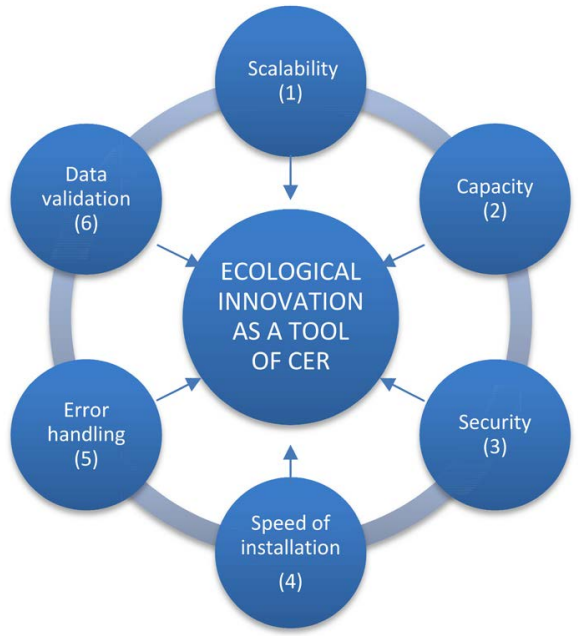

Model of Criteria of Eco-Innovation Efficiency in terms of CER.

\section{Appendix 2. Survey}

1) Do you believe that eco-innovation always requires making crucial changes, but at the same time leads to better performance outcomes and higher quality of the final product or service level? (Feel free to expand your response beyond yes and no options).

2) Do you think CER is being implemented too slowly, too quickly or at a proper pace in the current course of time? (Feel free to expand your response beyond yes and no options).

3) Do you believe that eco-innovation contributes to scalability of business? (Feel free to expand your response beyond yes and no options. Examples from your own experience would be appreciated). 
4) Do you regard eco-innovation as a threat to business? (Feel free to expand your response beyond yes and no options. Examples from your own experience would be appreciated).

5) How do you position security in the course of evaluation of efficiency of eco-innovation and CER implemented in modern business units? (Feel free to expand your response beyond yes and no options. Examples from your own experience would be appreciated).

6) What would be your recommendations for protecting and strengthening security in business under CER terms? (Feel free to expand your response beyond yes and no options. Examples from your own experience would be appreciated). 
7) Comment on the aspect of speed installation of eco-innovations in the modern business world. (Feel free to expand your response beyond yes and no options. Examples from your own experience would be appreciated).

8) What are your recommendations for improving the speed of installation? (Feel free to expand your response beyond yes and no options. Examples from your own experience would be appreciated).

9) Do you believe it is possible to predict and prevent errors in the process of eco-innovation implementation?

a) Yes

b) No

10) What are the main factors contributing to effective error handling? 
11) Is data validation a problematic issue in the process of eco-innovation?

a) Yes

b) No

12) List what you believe to be any of the main challenges and drawbacks faced in the context of data validation:

We would also highly appreciate any additional comments and examples you might wish to offer within the field of focus of the given research. Thank you in advance! 